\title{
Vivências maternas na realidade de ter um filho autista: uma compreensão pela enfermagem*
}

\author{
Maternal experiences in the reality of having an autistic son: an understanding for nursing
}

Experiencias maternas en la realidad de tener un hijo autista: una comprensión para la enfermería

\section{Claudete Ferreira de Souza Monteiro', Diana Oliveira Neves de Melo Batista", Edileuza Gonçalves de Carvalho Moraes", Tarcyana de Sousa Magalhães", Benevina Maria Vilar Teixeira Nunes', Maria Eliete Batista Moura' \\ 'Universidade Federal do Piauí. Faculdade NOVAFAPI. Terezina PI. \\ "Faculdade NOVAFAPI. Teresina, PI}

Submissão: 10/05/2007

Aprovação: 24/08/2008

\section{RESUMO}

Este estudo objetivou descrever a vivência de ser-mãe de criança autista. Utilizou-se abordagem Qualitativa e referencial fenomenológico com conceitos de Martin Heidegger. Foram entrevistadas 14 mães de crianças autistas, com perguntas abertas, gravadas e transcritas na íntegra. O cenário foi a AMA-PI e dados produzidos em maio de 2006. A análise revela Que as mães vivenciam a facticidade de ter um filho autista permeada por sentimentos de nulidade, fé e solidão. As mães também deixam de viver o seu cotidiano para viverem o cotidiano do filho. Ao assumirem sua condição existencial -estar-no-mundo e ser mãe de uma criança autista, passam a se compreenderem como ser capaz de lutar pelo bem-estar do filho, sem queixas, demonstrando abnegação, paciência e preocupação.

Descritores: Autismo; Fenomenologia; Enfermagem.

\section{ABSTRACT}

This study has as objective to describe the experience of being mother of an autistic child. A Qualitative approach was accomplished according to the phenomenological concepts of Martin Heidegger. Fourteen mothers of autistic children had been interviewed, with semi-structured Questions, tape-recorded and transcribed integrally. The local of data collection was the AMA-PI with data produced in May, 2006. The analysis revealed that mothers who live the facticity of having an autistic child is permeated by negative feelings, faith and solitudeness. Mothers also leave their dalily life to live their children's daily live. When assuming their existential condition - to be -in the world and to be mother of a autistic child, they begin to understand how to be capable to fight for their children's wellbeing, without complaints, demonstrating self-denial, patience and concern.

Descriptors: Autism; Phenomenology; Nursing.

\section{RESUMEN}

Este estudio que objetivó describir la experiencia de ser-madre del un niño autísta. El abordaje cualitativo fue utilizado según el referencial fenomenológico de Martín Heidegger. Catorce madres de niños autístas fueron entrevistadas con preguntas abiertas, grabadas y transcritas en la integra. El escenario de la investigación fue el AMA-PI y los datos producidos en mayo de 2006 . El análisis reveló las madres viven profundamente la facticidad de tener un hijo autísta la cual es permeada por sensaciones negativas, fe y la soledad. Las madres tanbién dejam vivir su vida diaria para vivir la vida diaria de sus hijos. Al asumir la condición existencial - estar en el mundo y ser madre de un niño autísta, ellas comenzan a comprender cómo son capazes de luchar por lo bien-estar de sus hojos, sin Quejas, demuenstrando abnegación, paciencia y preocupación.

Descriptores: Autismo; Phenomenology; Enfermería.

*Trabalho premiado no $58^{\circ}$. Congresso Brasileiro de Enfermagem - Prêmio lane Fonseca Proença. 


\section{INTRODUÇÃO}

Nos últimos seis anos a população de Teresina viu surgir organizações não governamentais voltadas a assistir crianças autistas. Embora o autismo não seja uma patologia de descoberta recente, no estado do Piauí com a chegada da Associação dos Amigos dos Autistas (AMA) tem sido difundido pela mídia e despertado interesse tanto da sociedade civil como de estudantes e profissionais da saúde para melhor conhecer e ajudar as crianças e seus familiares.

A dimensão e a gravidade das deficiências, de um modo geral, foram registradas pelo Instituto Brasileiro de Geografia e Estatística revelando Que $14,57 \%$ da população brasileira possui algum tipo de deficiência e que no Piauí os dados chegam à ordem de 17,60\% entre as deficiências, ocupando assim o $3^{\circ}$ lugar na classificação nacional ${ }^{(1)}$.

O fato do Estado do Piauí apresentar um número considerável de pessoas com deficiência e por ser o autismo um problema neurobiológico manifestado no geral, em crianças antes dos dois anos e meio de idade, as Quais se mostram aparentemente indiferentes ou mesmo avessas à demonstração de afeto e ao contato físico, mais caracterizado pela repetição e cronometragem de hábitos, nos estimularam a conhecer a vivência de mães de crianças autistas.

O autismo por ser uma síndrome Que tem como característica principal à invariância de hábitos e comportamentos ritualistas, exige da pessoa Que cuida total dedicação. Esta, em geral a mães, no decorrer do processo vivencial, vai se despersonificando, perdendo características do seu cotidiano e assumindo o cotidiano do filho, desse modo fechada para as possibilidades que a vida oferece.

A descoberta do autismo se dá em torno dos dois primeiros anos de vida e aQueles com Q.I. maior e capazes de falar, têm prognóstico mais favorável. Na vida adulta, os problemas de comunicação e socialização tendem a persistir, e apenas uma peQuena parcela alcança independência. Até o momento, não se alcançou à cura para o autismo, o tratamento visa ajudá-los a alcançar independência para atividades diárias, como vestir-se e se higienizar $^{(2)}$

Existem ainda outras manifestações Que caracterizam o autismo como comportamentos ritualistas, crise de birra, auto-agressividade, alterações no sono e alimentação, ausência de noções de perigo, hipo ou hiperreações a estímulos sensoriais como luz ou sons, bem como apego a datas e itinerários e ainda demonstração de predileção por objetos rígidos e incomuns e geralmente apresenta medo e fobia inespecíficos. A criança com esta síndrome não estabelece contatos físicos, visuais ou auditivos e nem tão pouco afetivos. $\mathrm{O}$ isolamento social também é marcante nestes portadores, sendo assim não demonstram interesse em participação de jogos cooperativos, brincadeiras em grupo, no entanto, podem surgir momentos de interações afetivas, mas da mesma forma Que elas surgem, elas desaparecem ${ }^{(3)}$.

Em estudo sobre a trajetória e a sobrecarga emocional da família de crianças autistas concluiu-se Que mães de crianças autistas vivenciam um estresse Que muitas vezes não se manifesta o Que deixa transparecer Que não é sacrificante cuidar de uma criança com autismo. Concluiu-se ainda Que a dedicação integral dessas mães culmina em um fechamento das mesmas para outras vivências. De uma forma geral, toda a família tem um prejuízo emocional com a situação de convivência com um membro autista ${ }^{(4)}$.

Partindo da problemática levantada, objetivou-se conhecer a vivência de ser-mãe de criança autista e compreender o sentido desta vivência.

\section{METODOLOGIA}

Estudo descritivo e analisado com o referencial da fenomenologia por este fazer um retorno às coisas nelas mesmas e ir à essência do próprio fenômeno, conhecê-lo tal Qual como se mostra. Etimologicamente a palavra fenomenologia é o estudo ou a ciência do fenômeno ${ }^{(5)}$. Esta é uma palavra de origem grega formada por phainomena que significa "fazer, aparecer, mostrar" e logos que é o fenômeno. Assim a fenomenologia como sendo o fenômeno naquilo Que se mostra, se revela, permite captar os fenômenos humanos em seu teor vivido ${ }^{(6)}$.

Para conhecer a vivência da mulher mãe de criança autista, algumas etapas foram seguidas tomando-se por base o modelo de estudo de Monteiro ${ }^{(7)}$, Que traz como etapa inicial o aproximar-se dos sujeitos. Neste estudo esta aproximação aconteceu na Associação dos Amigos dos Autistas (AMA/PI). Ali as mães foram convidadas a participarem do estudo e informadas dos objetivos, bem como da garantia do anonimato do seu nome. Elas foram receptivas e concordaram em participar do estudo, assinando o Termo de Consentimento Livre e Esclarecido, atendendo ao disposto na Resolução 196/96 do Conselho Nacional de Saúde (CNS). O estudo também recebeu aprovação do Comitê de Ética em Pesquisa da NOVAFAPI.

A segunda etapa foi instalar a atitude dialogal, criando um ambiente propício à fala das mães sobre o fenômeno, Que se faz pelo discurso. Na fenomenologia a linguagem permite Que torne realidade àQuilo Que faz sentido para o sujeito - $\mathrm{O}$ pesQuisador pergunta e o sujeito responde livremente o perguntado.

Como instrumento de produção de dados foi utilizado um roteiro de perguntas abertas, gravadores e fitas cassetes. As perguntas foram formuladas e as mães tiveram a liberdade para discorrer livremente sobre o perguntado. As entrevistas foram encerradas Quando houve saturação das mesmas e transcritas na íntegra logo após sua gravação para dar prosseguimento à etapa seguinte Que foi a leitura e releitura do material produzido, buscando compreender assim o vivido de ser-mãe de crianças autistas.

Para alcançarmos os objetivos propostos no estudo, o referencial da fenomenologia permitiu aproximar à essência do ser mãe de uma criança autista, ou seja, desvelar o sentimento da mãe, por meio de sua experiência vivida, explicado não pela filosofia ou ciências naturais, mas sim por aQuilo Que lhe vem à consciência

O cenário para o encontro com os sujeitos foi a AMA/PI, em Teresina-PI, instituição fundada em 2000, por um grupo de pais de autistas. É uma entidade sem fins lucrativos, beneficente, dirigida por pais ou responsáveis de portadores da Síndrome do Autismo e agrega como sócio QualQuer pessoa de boa vontade Que tenha como propósito ajuda voluntária. Objetiva, principalmente, a informação, o estudo, a pesquisa e o atendimento aos portadores desta síndrome e seus familiares, tendo como missão, proporcionar às pessoas com autismo e outros transtornos do desenvolvimento 
e seus familiares um atendimento integral, gratuito e de Qualidade, contribuindo para a criação de uma sociedade inclusiva, onde o potencial do portador de autismo seja aproveitado ao máximo e sejam também respeitados como cidadãos de direito.

A instituição tem atualmente 112 alunos matriculados e projeto de expansão para outras cidades. Seu espaço físico é bem estruturado, arborizado, possui salas de aula adequadas, banheiros adaptados, auditório amplo equipado com recursos audiovisuais e outros espaços, inclusive um playground e duchas. Conta com a colaboração de educadores Que são funcionários efetivos do Estado, à disposição da instituição. Estes desempenham um trabalho pedagógico dividido em níveis crescentes de complexidade.

\section{O referencial teórico de análise: fenomenologia segundo Martin Heidegger.}

Martin Heidegger foi um dos maiores filósofos do século XX, tendo nascido em Messkirch (Alemanha) em 26 de setembro de 1889 e faleceu em 26 de maio de 1976. Filho do sacristão Friedrich Heidegger e de Johanna. Heidegger ainda muito cedo demonstrou interesse por Questões religiosas, pretendeu ser padre chegando a ser seminarista ${ }^{(8)}$

Heidegger despertou para a filosofia ainda no tempo de seus estudos básicos. Foi discípulo de Edmund Husserl e estudou na Universidade de Freiburg, o fundador da fenomenologia, onde se tornou professor e posteriormente reitor. Tinha uma linguagem de difícil compreensão, mas apesar disto, era seguido por um grande número de pessoas que o admiravam pelos seus escritos e pensamentos sobre o Ser. A obra Ser e Tempo o destacou como o mais importante da filosofia existencialista. Nesta obra ele apresenta o método fenomenológico partindo da experiência vivencial para Questionar o ser, interrogar o ente e desvelar o sentido do ser ${ }^{(9)}$.

Em Ser e Tempo, Heidegger fala do homem, como ser singular, denominando-o de da-sein (pre-sença) Que se mostra na cotidianidade com formas de expressão Que podem ser autênticas, próprias e singulares ou inautênticas, impróprias e impessoais. $\mathrm{O}$ da-sein constitui-se num ente aberto às possibilidades, logo, em liberdade em seu modo de ser ${ }^{(10)}$.

Para o filosófo o ser humano em sua cotidianidade se constitui sob três perspectivas: a facticidade, a existencialidade e a decadência. A facticidade é o estar lançado no mundo, já a existencialidade corresponde à capacidade de ver, significar e apropriar-se das coisas do mundo a partir de sua própria perspectiva e a de-cadência é o abandonar-se em favor das ocupações e das ambigüidades Que lhe faz ter uma existência inautentica, própria da cotidianidade ${ }^{(10)}$.

Nesta existência inautêntica o homem nega a si próprio em detrimento dos outros, mergulhando-se no profundo anonimato do ser social.

Ao contrário, na existência autêntica o homem é colocado como verdadeiro revelador do ser, por este ter Que emergir da angústia para se colocar no seu devido lugar de da-sein. Heidegger diz que a angústia é o sentimento da existência humana capaz de fazer com Que o homem (da-sein) se reconheça como um ser aberto às possibilidades e que pode ser reconduzido ao encontro de sua totalidade. Esta angústia leva o da-sein a fugir da traição contra si mesmo Quando este é imerso na monotonia da vida cotidiana e se deixa dominar pelas mesQuinharias do dia-a-dia. A partir da angústia o homem percebe-se como um ser-para-a-morte e, segundo Heidegger, Quando isto ocorre ou ele foge para a vida cotidiana e assume a inautenticidade da existência ou manifesta seu poder de transcendência sobre o mundo e sobre si mesmo ${ }^{(10)}$.

O ser humano assim compreendido é para o filósofo um ser-aí Que se constitui como ser-no-mundo e ser-com-os-outros existencialmente na con-vivência, nas relações Que estabelece, no cuidado e na ocupação. Assim ele se envolve na cotidianidade pela solicitude, consideração e paciência ${ }^{(10)}$.

\section{RESULTADOS E DISCUSSÃO}

Foram entrevistadas 14 mulheres com faixa etária de 30 a 64 anos, a maioria casada, do lar, com nível médio de escolaridade e de religião católica. $\mathrm{O}$ fato dessas mulheres não exercerem atividade ocupacional fora de casa, se dá pela necessidade de cuidados que a condição do filho requer. Elas têm uma rotina diária Que inclui os afazeres domésticos, cuidados pessoais e familiares e prioritariamente os cuidados Que envolvem o filho, acarretando assim em acúmulos de responsabilidades, Que terminam por contribuir para o afastamento ou abandono de seus sonhos e desejos pessoais.

Os discursos foram lidos, relidos e identificados em unidades comuns Que agrupadas se constituíram em Quatro categorias de análises.

\section{Vivenciando a Facticidade de Ter um Filho Autista}

A facticidade consiste no fato do ser humano encontrar-se no mundo, disposto e a mercê das situações cotidianas sem Que para isso tenha participado dessas decisões. O mundo no Qual é lançado ultrapassa o espaço geográfico e se constitui pelo conjunto histórico, social e econômico no Qual se encontra imerso ${ }^{(10)}$.

Nos discursos das mães compreende-se Que inicialmente ter um filho autista não era algo seQuer imaginável e Que essa realidade muda à compreensão de sua própria existência. A mulher ao engravidar planeja um novo mundo no eual o filho passa a ocupar o centro desse mundo, mas sempre o imaginando saudável. O ser humano tem essa capacidade de no hoje sempre projetar o amanhã. Para as mulheres deste estudo durante o período gravídico a projeção do futuro sempre foi de ser mãe de um bebê perfeito.

Teve uma mudança um pouQuinho brusca, porQue a gente faz um planejamento familiar, esperando uma criança sem nenhum tipo de problema e infelizmente aconteceu. (DI4).

Eu me senti uma pessoa inútil porque ia ter uma pessoa excepcional. $O$ que eu Queria era que ele fosse uma criança normal, mas como não é, fazer o Quê?(DIO).

Após o diagnóstico do meu filho mudou muita coisa, é como se tivesse que controlar tempo e esquematizar tudo. (DI).

$\mathrm{Na}$ facticidade, no estar-lançado, algumas coisas boas são relatadas pelas mâes, como uma oportunidade de ajudá-las na realidade de ter um filho autista. As mães referem à Associação de Amigos Autistas (AMA), como um espaço onde os filhos têm conseguido avançar principalmente na linguagem.

Ele faz tratamento aqui na AMA. Graças a Deus o 
aproveitamento dele na AMA tem sido até satisfatório, porQue Quando ele chegou aQui na $A M A$, pouco falava e agora ele se comunica bem com as pessoas. (D. I3)

Depois que ele entrou na AMA, melhorou muito, hoje ele anda, não tem nenhum defeito físico, ele fala bastante, repete tudo que ele faz no dia-a-dia. (D. I2)

A AMA como espaço de apoio ao cuidar do filho desde sua criação representa um local onde as mães e as crianças autistas depositam parte de suas possibilidades e muito tem contribuído para Que essas crianças possam desenvolver a sociabilização, a comunicação e a imaginação e até a desenvolver pequenas tarefas como a de pegar em um lápis para escrever seu próprio nome.

Todo o trabalho desenvolvido pela referida instituição não visa somente o tratamento, mas também a inclusão social tanto dessas crianças Quanto da família, para Que esses possam ter assegurado seus direitos como cidadãos.

Para as mães passar alguma parte do cotidiano na associação permite o contato com outras mães e profissionais podendo assim se descobrir e associar outras experiências como lição para elas mesmas.

Busquei a AMA e bati na porta certa. Eu estou descobrindo ele e me descobrindo. Aqui ele vai progredir mais, vai consequir independência e a cada depoimento de outras mães para mim é uma lição. (D 06)

A fenomenologia Heideggeriana remete a compreensão de Que as mães encontram várias maneiras de se sentirem como os outros. Os depoimentos mostram como elas se relacionam com os filhos e com os entes Que encontram na AMA se assemelhando e se espelhando em outras mães Que são como referenciais para ela. $\mathrm{O}$ relacionar-se com alguém, com o outro de maneira envolvente e significante é o Que Heidegger chama de "solicitude"(7).

A procura pela AMA é movida pelo cuidado. "O ser humano tem consigo o cuidado pela própria vida, tornando-se responsável por ela, procurando por todos os meios para preservá-la e desenvolvêla"(II). É esse cuidado Que aproxima as mães da AMA. Ali elas se relacionam com outras mães com sentimentos semelhantes, e buscam os recursos terapêuticos de Que necessitam para o filho e para si.

Descobrir-se como mãe de uma criança autista rompe com sonhos e desejos. As mães se vêem lançadas num mundo do Qual não se pode fugir e se sentem impotentes e inúteis e buscam além da AMA outras forças para enfrentarem a facticidade de terem um filho autista. É na fé e confiança em um ser sobrenatural Que se desvela no discurso como um presente e uma dádiva de Deus. A força provém da crença em um ser superior Que funciona como auxílio e minimizam sentimentos de nulidade ${ }^{(11)}$.

Eu entrego minha vida completamente para o meu filho, assim como Jesus entregou a sua vida para nos salvar, eu também entrego a minha vida para ele. Sou abençoada por Deus, porQue foi um anjo Que Jeová me deu. (DI I).

Foi Deus que botou para eu cuidar dele. Deus colocou ele assim na minha mão. (DI0)

A maioria dessas mães busca força para enfrentar as tarefas de lidar com o filho autista em um ser superior, em Deus, atribuindo até a uma bênção de Deus em suas vidas, aceitando com naturalidade, como se fosse uma coisa pré-determinada, encarando até como um "privilégio" ser mãe de uma criança autista.

\section{Se Deus escolheu a nossa casa, é porque Ele vai nos dá condição} para cuidar dela, até enquanto Ele Quiser. (D3)

Pra mim é como se fosse fazer um bem na terra, acredita? Eu entrego pra Deus minha vida.(D5)

Quando as mães, sujeito deste estudo se referem a fé como modo de confiança, e de esperança, esse sentimento surgi positivamente e estas mães, como ser-aí Que habita vários mundos, o mundo da casa, o mundo da AMA, o mundo do filho, o acreditar em um ser sobrenatural as auxiliam frente aos transtornos presente a facticidade existencial. Este sentimento de positividade revela Que a impotência do vivido no cotidiano destas mães ante ao fato de ter e cuidar do filho autista as faz reunir forças para o enfrentamento complementando o fazer humano com fazer divino.

\section{A De-cadência: Vivenciando o Cotidiano do Filho}

Ao ser lançada no mundo, o ser vive seu cotidiano ôntico a cada instante e nesse viver vai ao encontro do outro. A convivência cotidiana o coloca sob a tutela dos outros, na verdade os outros dispõem sobre as suas possibilidades cotidianas. Neste estudo a mãe absorve o mundo do filho, referindo-se e cuidando envolvidamente nesse mundo, de tal forma Que passa a relatar o seu cotidiano como o cotidiano do filho, sustentando sua vivência no modo do desvelo e do cuidar.

O meu dia a dia é assim, se ele está bem eu estou bem também, se ele fica mal eu fico mal. Quando ele está bem ele canta, ele dança, eu canto com ele e na hora que ele está mal, meu coração fica mal demais. (DI0)

Vivo direito com ela, atrás, seguindo os passos dela, vendo o Que ela vai fazer. (D I I)

Tenho que dar banho, as necessidades dela eu que tenho que cuidar, a comida eu tenho que dar no ponto dela comer. (DI2)

Enquanto ele está dormindo a gente aproveita o tempo livre para fazer o maior número de atividades em casa, mas ele está tão acostumado comigo e eu com ele que a gente faz tudo junto, normal com ele e tudo vai fazendo e ele vai olhando. (DI)

O domínio dos outros sem surpresas é assumido sem Que o sercom se dê conta ${ }^{(10)}$. As mães participantes deste estudo assim se revelam, não como elas mesmas, mas como se o próprio filho lhes tomasse o ser dispondo sobre suas possibilidades cotidianas. Demonstram uma árdua luta em busca de assumir o cuidado com o filho. O cuidado representa um complexo diário no Qual se sentem presas e dominadas. No geral relatam um cotidiano Que é o do 
filho e o pouco Que se distanciam limitam-se aos afazeres domésticos e mesmo Quando saem Quase sempre é para a AMA afim de levar o filho para participar das atividades e ali ficar esperando e voltar para casa. Nenhuma das depoentes trabalha fora de casa.

Eu já trabalhei, mas no momento não posso desde Que ele nasceu Que caminho com ele para APAE, fisioterapia e agora para a AMA. Tenho Que ficar a tarde aQui com ele e pela manhã. (DI)

Nunca trabalhei, só sou do lar mesmo e venho para cá (AMA) de tarde e na parte da manhã eu estou em casa. Cuido mesmo da casa, da comida, da roupa e Quando saio para rua só se for assim comprar umas coisinhas. (D2)

Nesse cotidiano as mães vão aos poucos perdendo sua própria história e passam a viver a história do filho. Os afazeres domésticos, os utensílios passam a ter significação e é esse mundo percebido somente pelo ambiente doméstico que faz sentido, ele é a referência. Mas o "mundo ambiente não é o mundo em si. É a primeira referência decisiva a uma estrutura do mundo" ${ }^{(8)}$.O mundo vai mais além, compreender as relações de um ser com o outro, é a própria história vivida no contexto social, de trabalho, de projeções e de significação ${ }^{(10)}$.

\section{A Existencialidade: a Vivência de Ser Mãe de uma Criança Autista}

Ser mãe de uma criança especial é assumir-se como mãe também especial, superando todos os obstáculos de comunicação e relacionando-se com o filho. É assumir responsabilidade pelo cuidar, é dar amor incondicional, é ter paciência e ser privilegiada.

É ter paciência. Eu tenho paciência, eu sei esperar o momento da crise passar, eu fico meio machucada. Eu me acho uma pessoa privilegiada. Eu entendo ele, ele não fala, mas eu sei o que ele Quer, então eu me sinto até superior a outras mães. Podem sorrir na minha frente ou ficar dando risadas que eu nem me importo. (D 10)

É ser especial. Eu gosto do meu filho autista e não tenho medo de ser mãe de um autista. É o amor da minha casa. (DI I)

É ter Que superar. (DI2)
Acho Que a gente se apega demais, fica mais ligado. (DI)

Eu me sinto até assim superior a outras mães normais eu já aceitei e sinto prazer em andar com ele. Sou eu que cuido dele. (DIO).

Ao assumirem sua condição existencial, ou seja estar-no-mundo e ser mãe de criança autista, as mães passam a se compreenderem como ser capaz de lutar pelo bem-estar dos filhos, sem Queixas, sem rancor, mas demonstrando abnegação, paciência e preocupação, transformando assim a condição dolorosa em uma condição de orgulho e superioridade. A pré-sença abre para si mesma seu próprio ser, e esta abertura elimina obstruções, encobrimentos, obscurecimentos e se mostra por si mesma ${ }^{(10)}$. Assim as mães se mostram e se revelam como mães especiais.

\section{CONSIDERAÇÕES FINAIS}

Ser mãe de uma criança autista vai da superação ao privilegio. É colocar-se em patamar diferenciado, é ser também especial, pois o Que sente o filho parece sentir a mãe. O cotidiano do filho é também vivido pela mãe. Entretanto, em nenhum dos discursos as mães se lançam como ser de possibilidade, todas elas vivem exclusivamente para o lar e o cuidar dedicado ao filho é incondicional.

Compreender essas mulheres, mães de crianças autistas foi vêlas de forma individual e singular, e ir de encontro àQuilo que estava velado, Que era desconhecido, mas que se mostrou ou se revelou através dos seus gestos, atitudes ou sentimentos .

A enfermagem Que tem o cuidar como ação primeira deve voltar-se não somente para a criança autista mas também para as mães destas crianças, cujo ex-sistir é encoberto pelo ex-sistir do filho. A enfermagem implica em auxiliar as pessoas a buscarem um caminho que lhes mostre o sentido do cuidado, numa compreensão de transcendência de serno-mundo-com-o-outro, cuidando-se e cuidando ${ }^{(12)}$.

Assim, este estudo traz uma nova reflexão para o relacionamento Que deve existir entre a equipe de enfermagem e mães de filhos especiais, como são as mães de filhos autistas. Apesar de se considerarem também especiais, a enfermagem deve compreender que o sofrimento Que as acompanha pode estar camuflado por aparente abnegação e valor. Na verdade são mães Que também precisam ser cuidadas, prevenindo o adoecimento psíeuico e contribuindo para Que elas possam cuidar do filho e também se cuidarem.

\section{REFERÊNCIAS}

I. Instituto Brasileiro de Geografia e Estatística. Ministério do Planejamento, Orçamento e Gestão (BR). 2006. [citado 15 maio 2006]. Disponível em: URL: http://www.ibge.gov.br/.

2. Almedia OP, Drateu L, Laranjeira R. Manual de psiquiatria. Rio de Janeiro(RJ): Guanabara Koogan; 1996.

3. Camargo lúnior W. Transtornos invasivos do desenvolvimento. Brasília (DF): Corde; 2002.

4. Fávero MAB. Trajetória e sobrecarga emocional da família de crianças autistas: relatos maternos [dissertação]. Ribeirão Preto (SP): Faculdade de Filosofia, Ciências e Letras de Ribeirão Preto, Universidade de São Paulo; 2005.
5. Dartigues A. O Que é fenomenologia. $8^{\mathrm{a}}$ ed. São Paulo (SP): Centauro; 2002.

6. Inwood MJ. Dicionário Heidegger. Rio de Janeiro (RJ): Jorge Zahar; 2002

7. Monteiro CFS. Marcas no corpo e na alma de mulheres Que vivenciaram a violência conjugal: uma compreensão pela Enfermagem [tese]. Rio de Janeiro (RI): Escola de Enfermagem Anna Nery, Universidade Federal do Rio de Janeiro; 2005.

8. Stein E. Introdução ao pensamento de Martin Heidegger. Porto Alegre (RS): Edipucrs; 2002.

9. Cobra RQ. Vida, época, filosofia e obras de Martin Heidegger; 
Vivências maternas na realidade de ter um filho autista: uma compreensão pela enfermagem

2001. [citado 15 mai 2006]. Disponível em: URL: http:// www.cobra.pages.nom.br/fc-heidegger.html.

10. Heidegger M. Ser e Tempo. Parte I. $12^{\text {a }}$ ed. São Paulo (SP): Vozes; 2002.

1 I. Salimena AMO, Cadete MMR. Desvelando os sentimentos da mãe ao deixar o filho à porta da sala de cirurgia. Enfermagem
Atual 2002; 2(24): 33-8.

12. Silva LWS, Francione FF, Sena ELS, Carraro TE, Randiniz VO. Cuidado na perspectiva de Leonardo Boff: uma personalidade a ser(re)descoberta na enfermagem. Rev Bras Enferm 2005; 58(4): 471-5. 